\title{
Three-Amino Acid Spacing of Presenilin Endoproteolysis Suggests a General Stepwise Cleavage of $\gamma$-Secretase-Mediated Intramembrane Proteolysis
}

\author{
Akio Fukumori, ${ }^{1,2}$ Regina Fluhrer, ${ }^{1,2}$ Harald Steiner, ${ }^{1,2}$ and Christian Haass ${ }^{1,2}$ \\ ${ }^{1}$ DZNE - German Center for Neurodegenerative Diseases, Munich, and ${ }^{2}$ Adolf Butenandt Institute, Biochemistry, Ludwig Maximilians University Munich, \\ 80336 Munich, Germany
}

\begin{abstract}
Presenilin (PS1 or PS2) is the catalytic component of the $\gamma$-secretase complex, which mediates the final proteolytic processing step leading to the Alzheimer's disease (AD)-characterizing amyloid $\beta$-peptide. PS is cleaved during complex assembly into its characteristic $\mathrm{N}$ - and C-terminal fragments. Both fragments are integral components of physiologically active $\gamma$-secretase and harbor the two critical aspartyl residues of the active site domain. While the minimal subunit composition of $\gamma$-secretase has been defined and numerous substrates were identified, the cellular mechanism of the endoproteolytic cleavage of PS is still unclear. We addressed this pivotal question by investigating whether familial AD (FAD)-associated PS1 mutations affect the precision of PS endoproteolysis in a manner similar to the way that such mutations shift the intramembrane cleavage of $\gamma$-secretase substrates. We demonstrate that all FAD mutations investigated still allow endoproteolysis to occur. However, the precision of PS1 endoproteolysis is affected by PS1 mutations. Comparing the cleavage products generated by a variety of PS1 mutants revealed that specifically cleavages at positions 293 and 296 of PS1 are selectively affected. Systematic mutagenesis around the cleavage sites revealed a stepwise three amino acid spaced cleavage mechanism of PS endoproteolysis reminiscent to the $\varepsilon^{-}, \zeta$-, and $\gamma$-cleavages described for typical $\gamma$-secretase substrates, such as the $\beta$-amyloid precursor protein. Our findings therefore suggest that intramembranous cleavage by $\gamma$-secretase and related intramembrane-cleaving proteases may generally occur via stepwise endoproteolysis.
\end{abstract}

\section{Introduction}

$\gamma$-Secretase catalyzes the second and final processing step of the $\beta$-amyloid precursor protein (APP), releasing the neurotoxic amyloid $\beta$-peptide $(\mathrm{A} \beta)$, which is implicated in Alzheimer's disease (AD) pathogenesis (Haass and Selkoe, 2007). The protease is composed of four subunits (Steiner et al., 2008; Wolfe, 2009), presenilin 1 (PS1) or PS2, nicastrin (NCT), anterior pharynx defective-1a (APH-1a) or APH-1b, and presenilin enhancer-2 (PEN-2), which are necessary and sufficient for $\gamma$-secretase activity (Edbauer et al., 2003). PSs contain two aspartyl residues within transmembrane domains (TMDs) 6 and 7, which are part of the catalytic domain of $\gamma$-secretase (Wolfe et al., 1999). Pivotal findings by Thinakaran et al. (1996) demonstrated that PS is endoproteolysed into an $\mathrm{N}$-terminal and C-terminal fragment (NTF/CTF), which remain associated (Capell et al., 1998;

Received March 21, 2010; accepted April 20, 2010.

This work was supported by the Center for Integrated Protein Science Munich, the Sonderforschungsbereich Molecular Mechanisms of Neurodegeneration (SFB 596), Deutsche Forschungsgemeinschaft Grant HA1737/11-2, and the Alzheimer Research Award of the Hans and Ilse Breuer Foundation (H.S.). C.H. is supported by a "Forschungsprofessur" of the Ludwig Maximilians University. We thank Bart De Strooper for PS ${ }^{-1-}$ MEF cells, Alison Goate for the APPsw-6myc construct, Ralph Nixon and E. Kremmer for monoclonal antibodies, and Dr. Stefan Lichtenthaler for critically reading the manuscript.

Correspondence should be addressed to either Harald Steiner or Christian Haass, DZNE - German Center for Neurodegenerative Diseases, Munich; Adolf Butenandt Institute, Biochemistry, Ludwig Maximilians University Munich, Schillerstrasse 44, 80336 Munich, Germany. E-mail: hsteiner@med.uni-muenchen.de or chaass@med. uni-muenchen.de.

DOI:10.1523/JNEUROSCI.1443-10.2010

Copyright $\odot 2010$ the authors $\quad 0270-6474 / 10 / 307853-10 \$ 15.00 / 0$
Thinakaran et al., 1998; Yu et al., 1998). In fact in vivo endogenous PS largely exists as cleaved forms, while only very little full-length PS can be detected (Thinakaran et al., 1996). Endoproteolysis occurs within the domain encoded by exon 9 and is inhibited by a FAD-associated PS mutation lacking this domain (Thinakaran et al., 1996). Sequence analysis revealed that the $\mathrm{N}$ terminus of the PS1 CTF predominantly begins with amino acid 299 (Podlisny et al., 1997). However, additional cleavage sites after amino acids 291 and 292 were detected as well (Podlisny et al., 1997). Interestingly, mutagenesis demonstrated that the exchange of methionine 292 to aspartate of PS1 is sufficient to fully abolish endoproteolysis (Steiner et al., 1999b), raising the possibility that endoproteolysis may be initiated at amino acid 292 and then proceed C-terminal to finally cleave after amino acid 298. Very similar observations were made for PS2, suggesting a functional conservation of proteolytic trimming of the PS CTFs (Shirotani et al., 1997; Jacobsen et al., 1999). Endoproteolysis of PS is the last step during $\gamma$-secretase complex assembly and maturation (Haass, 2004). It is therefore widely believed to reflect an active state of $\gamma$-secretase (Xia, 2008), capable to efficiently perform intramembrane proteolysis of its substrates although the functional consequences of endoproteolysis are not resolved, since uncleaved PS derivatives can be active (Thinakaran et al., 1996; Steiner et al., 1999b) or inactive (Steiner et al., 2000; Laudon et al., 2004; Wang et al., 2004, 2006; Nakaya et al., 2005). There is compelling evidence that PS may be cleaved by autoproteolysis (Steiner et al., 1999c; Wolfe et al., 1999; Beher et al., 2001; 
Campbell et al., 2002, 2003; Edbauer et al., 2003; Nyabi et al., 2003; Xia, 2003). However, cleavage by an independent proteolytic activity has also been reported (Campbell et al., 2003; Nyabi et al., 2003). Furthermore, mutations at the PS active site (such as G384P and others) were identified, which allow efficient PS endoproteolysis but lose their ability for substrate cleavage (Steiner et al., 2000), a finding that may potentially challenge the hypothesis that PS cleavage occurs by autoproteolysis. So far, very little is known about the molecular mechanisms behind PS endoproteolysis (Xia, 2008). We now provide data to suggest that PS endoproteolysis occurs in a stepwise autoproteolytic manner very similar to that proposed for the processing of $\gamma$-secretase substrates such as APP (Takami et al., 2009).

\section{Materials and Methods}

Antibodies. Mouse monoclonal and rabbit polyclonal antibodies against the PS1 NTF (PS1-N) and the PS1 CTF (3027), respectively, were described before (Capell et al., 1997; Walter et al., 1997). Rat monoclonal antibody $2 \mathrm{D} 8$ to $\mathrm{A} \beta_{1-16}$ and rabbit polyclonal antibody 3552 to $\mathrm{A} \beta_{1-40}$ were described previously (Yamasaki et al., 2006; Shirotani et al., 2007). Mouse monoclonal antibody $4 \mathrm{G} 8$ to $A \beta_{17-24}$ was obtained from Covance Research Products. Monoclonal antibodies to c-myc (9E10) and FLAG epitopes (M2) were obtained from Dr. E. Kremmer (Forschungszentrum für Umwelt und Gesundheit, Munich, Germany) or SigmaAldrich, respectively.

cDNA constructs. To generate PS1 FTEV, a FLAG-epitope tag followed by the TEV protease recognition site (DYKDDDDKENLYFQG) was inserted after E321 of PS1 wt by QuikChange (Stratagene) mutagenesis using appropriate primers and pcDNA3.1/zeo+::PS1 as template. PS1 FTEV derivatives were generated likewise. cDNA constructs encoding PS1 $\Delta$ exon9 and PS1 G384P have been described before (Steiner et al., 1999a, 2000). The corresponding double mutant PS1 $\Delta$ exon9/G384P was generated by QuikChange mutagenesis. All constructs were confirmed by DNA sequencing. The APPsw6 myc construct has been described previously (Wang et al., 2004).

Cell culture, cell lines, and cDNA transfections. HEK293 cells stably expressing APPsw or stably coexpressing APPsw and PS1 were cultured as described previously (Moehlmann et al., 2002). PS1 FTEV constructs were stably transfected into HEK293 cells stably expressing APPsw by Lipofectamine 2000 (Invitrogen) and selected for Zeocin resistance $(200 \mu \mathrm{g} / \mathrm{ml})$ according to the instructions of the manufacturer (Invitrogen). Mouse embryonic fibroblast (MEF) cells derived from PS1/2 double knock-out mice (PS ${ }^{-1-}$ ) (Herreman et al., 1999) were cultured and transiently transfected as described previously (Yamasaki et al., 2006). Human neuroglioma H4 cells were cultured in Iscove's Modified Dulbecco's Medium (Invitrogen) supplemented with $10 \%$ fetal bovine serum and $1 \%$ penicillin/streptomycin and stably transfected as described for HEK293 cells.

$\mathbf{E}$
A

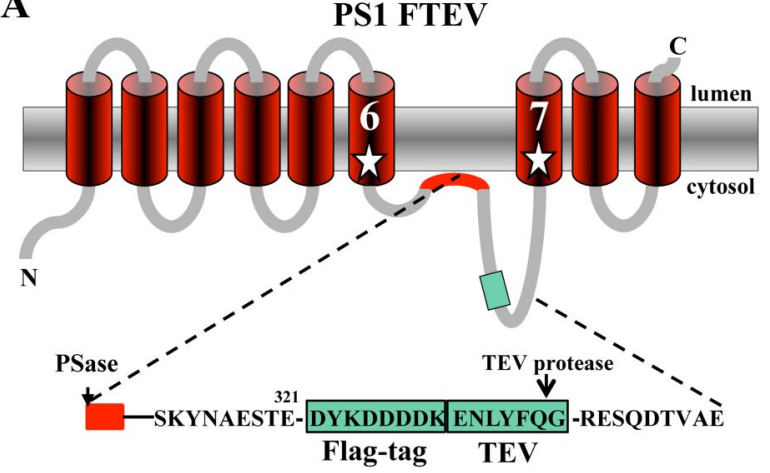

C

D
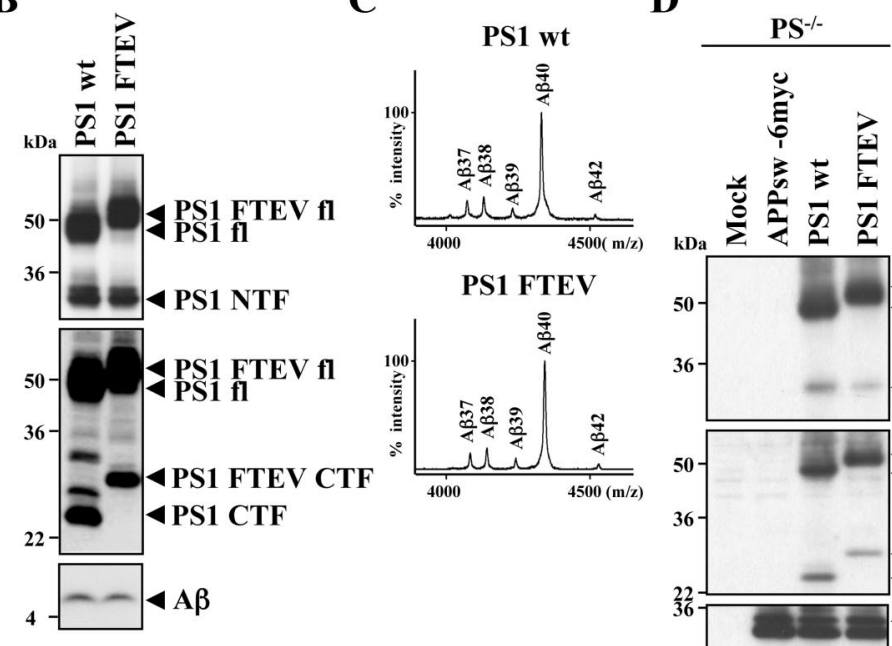

$\mathbf{P S}^{-/-}$
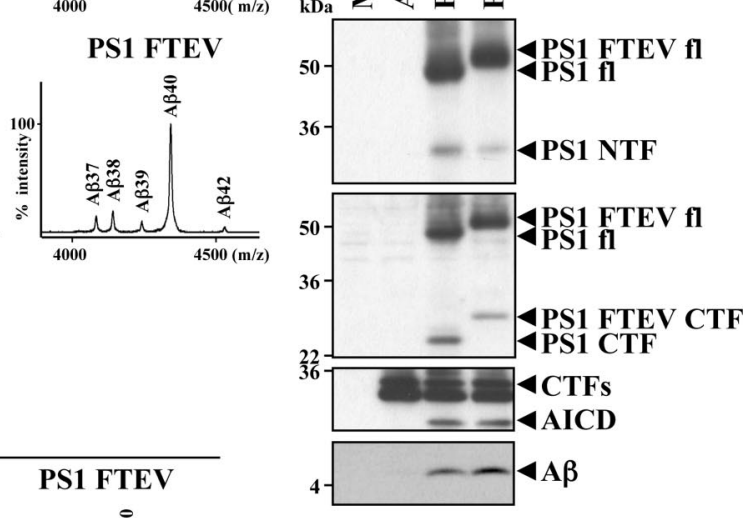

Figure 1. PS1 FTEV is proteolytically active. $A$, Schematic representation of PS1 FTEV depicting the sites of FLAG epitope and TEV cleavage site insertion (green box) C-terminal to the PS cleavage site domain (red) within the large cytoplasmic loop. Anti-Flag IP allows the isolation of PS1 FTEV CTFs derived from PS endoproteolysis. To allow the identification of the respective cleavage sites, the corresponding peptides are released by subsequent TEV protease cleavage (occurring between $Q$ and $\mathrm{G}$ ) and subjected to MS analysis. $\boldsymbol{B}$, Expression and endoproteolysis of PS1 FTEV were analyzed by immunoblotting of cell lysates of HEK293/sw cells stably expressing wt PS1 or PS1 FTEV using antibodies PS1-N to the PS1 N terminus (top) or antibody 3027 to the PS1 C terminus (middle panel) of PS1. Note that the endogenous PS1 CTF is replaced by the larger CTF derived from ectopically expressed PS1 FTEV. $\gamma$-Secretase activity of PS1 FTEV was analyzed by determining total A $\beta$ levels by immunoblot analysis using antibodies 2D8 (bottom). C, $\gamma$-Secretase cleavage specificity of PS1 FTEV was assessed by IP/MS analysis of A $\beta$ peptides from conditioned media. $\boldsymbol{D}, \boldsymbol{E}$, Expression, endoproteolysis, and $\gamma$-secretase activity of PS1 FTEV were analyzed by immunoblotting of cell lysates of PS ${ }^{-1-}$ cells transiently cotransfected with APPsw-6myc and wt PS1 or PS1 FTEV using N- and C-terminal antibodies to PS1 as in B (upper two panels), by immunoblot analysis of AICD using anti-myc antibody $9 \mathrm{E} 10$, and by combined immunoprecipitation/immunoblotting of $A \beta$ using antibodies 3552/2D8 (lower two panels) (D). Profiles of $A \beta$ peptides generated by PS $^{-1-}$ cells transiently cotransfected with APPsw-6myc and wt PS1 or PS1 FTEV were analyzed from conditioned media by IP/MS analysis $(\boldsymbol{E})$ as in $\boldsymbol{C}$.

Protein analysis. HEK293 cells were lysed in lysis buffer (4\% DDM, $0.1 \% \mathrm{~N}$-octylglucoside, $10 \mathrm{~mm}$ Tris-HCl, $\mathrm{pH}$ 8.0, $5 \mathrm{~mm}$ EDTA, and 140 $\mathrm{mm} \mathrm{NaCl}$ ) containing protease inhibitor mix (Sigma-Aldrich) for $20 \mathrm{~min}$ on ice. Following a clarifying spin at $13,000 \times g$ for $20 \mathrm{~min}$, equal amounts of protein were separated by $10 \%$ Tris-glycine urea SDS-PAGE. Full-length PS1 and its NTF and CTF were analyzed by immunoblotting of cell lysates using antibodies PS1-N or 3027, respectively. Analysis of total levels of secreted $\mathrm{A} \beta$ was performed by combined immunoprecipitation/immunoblotting of media conditioned for $16 \mathrm{~h}$ using antibodies $3552 / 2 \mathrm{D} 8$ or by direct immunoblotting using antibody $2 \mathrm{D} 8$. A $\beta$ species 
A

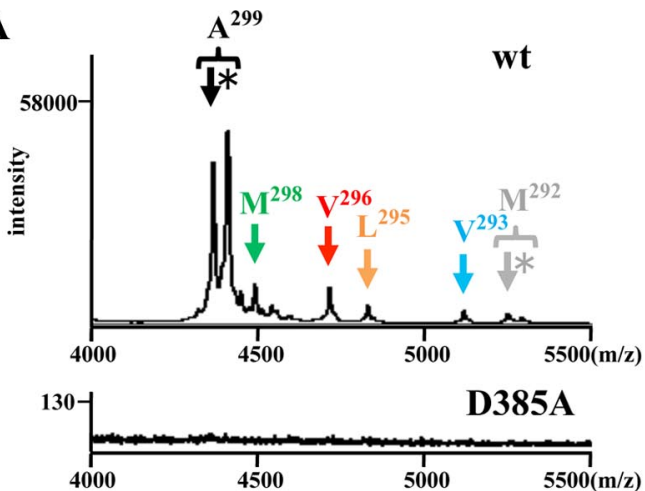

B

\begin{tabular}{|c|r|c|c|}
\hline Name & Sequence & Mass (calc.) & Mass (obs.) \\
\hline Ac-M $^{292} *$ & Ac-MVWLVNMAEGDPEAQRRVSKNSKYNAESTEDYKDDDDKENLYFQ & $\mathbf{5 2 7 2 . 7}$ & $\mathbf{5 2 7 2 . 6}$ \\
\hline $\mathrm{M}^{292}$ & MVWLVNMAEGDPEAQRRVSKNSKYNAESTEDYKDDDDKENLYFQ & $\mathbf{5 2 3 0 . 7}$ & $\mathbf{5 2 3 0 . 6}$ \\
\hline $\mathrm{V}^{293}$ & VWLVNMAEGDPEAQRRVSKNSKYNAESTEDYKDDDDKENLYFQ & $\mathbf{5 0 9 9 . 5}$ & $\mathbf{5 0 9 9 . 4}$ \\
\hline $\mathrm{L}^{295}$ & LVNMAEGDPEAQRRVSKNSKYNAESTEDYKDDDDKENLYFQ & $\mathbf{4 8 1 4 . 2}$ & $\mathbf{4 8 1 4 . 2}$ \\
\hline $\mathrm{V}^{296}$ & VNMAEGDPEAQRRVSKNSKYNAESTEDYKDDDDKENLYFQ & $\mathbf{4 7 0 1 . 0}$ & $\mathbf{4 7 0 1 . 0}$ \\
\hline $\mathrm{M}^{298}$ & MAEGDPEAQRRVSKNSKYNAESTEDYKDDDDKENLYFQ & $\mathbf{4 4 8 7 . 8}$ & $\mathbf{4 4 8 7 . 8}$ \\
\hline Ac-A $^{299} *$ & Ac-AEGDPEAQRRVSKNSKYNAESTEDYKDDDDKENLYFQ & $\mathbf{4 3 9 8 . 7}$ & $\mathbf{4 3 9 8 . 6}$ \\
\hline $\mathbf{A}^{299}$ & AEGDPEAQRRVSKNSKYNAESTEDYKDDDDKENLYFQ & $\mathbf{4 3 5 6 . 6}$ & $\mathbf{4 3 5 6 . 6}$ \\
\hline
\end{tabular}

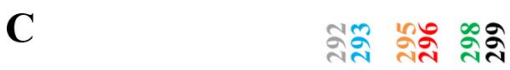

$\nabla \nabla \nabla \nabla$

...QERNETLFPALIYSSTMVWLVNMAEG... --FLAG-TEV

Figure 2. PS endoproteolysis occurs via multiple cleavages. $A$, Mass spectrum of peptides derived from PS endoproteolysis of PS1 FTEV stably expressed in HEK293 cells. PS1 FTEV CTFs were isolated by anti-Flag IP and subjected to TEV protease cleavage followed by MALDI-TOFMS. Peaks are labeled with colored letters corresponding to their $\mathrm{N}$-terminal amino acids. Asterisks indicate presumably N-terminally acetylated peptides. Note that no peptides were observed for the PS1 FTEV D385A active site mutant. B, Table of calculated and observed molecular masses of peptides derived from PS endoproteolysis of PS1 FTEV.C, Illustration of PS endoproteolysis sites identified. The hydrophobic region harboring the sites of PS endoproteolysis is shown in red. Arrowheads indicating the sites of PS endoproteolysis are colored according to the respective peptide peaks observed in the mass spectrum shown in $\boldsymbol{A}$.

were analyzed by immunoprecipitation/mass spectrometry (IP/MS) as described previously except that antibody 4G8 (Covance Research Products) was used as capture antibody. AICD was analyzed by immunoblotting of cell lysates using anti-myc antibody 9E10.

Mass-spectrometry analysis of PS endoproteolysis. Cells $\left(10^{8}\right.$; HEK293, $\mathrm{H} 4$, or PS ${ }^{-1-}$ MEF) stably or transiently expressing wt and mutant PS1 FTEV constructs, respectively, were harvested in PBS. Cell pellets were frozen in liquid nitrogen and stored at $-80^{\circ} \mathrm{C}$ until use. Cell lysates were prepared as above, subjected to a second clarifying spin by centrifugation at $100,000 \times g$ for $1 \mathrm{~h}$, and incubated with anti-FLAG M2-agarose (Sigma-Aldrich) overnight by rotation. Beads were washed three times with IP/MS buffer $(0.1 \% \mathrm{~N}$-octylglucoside, $10 \mathrm{~mm}$ Tris-HCl, $\mathrm{pH} 8.0,5$ mM EDTA, and $140 \mathrm{~mm} \mathrm{NaCl}$ ) and two times with water. Immunoprecipitated proteins were eluted with $100 \mathrm{~mm}$ glycine, $\mathrm{pH} 2.5$, and promptly neutralized with $1 / 8$ volume of $1 \mathrm{~m}$ Tris- $\mathrm{HCl}, \mathrm{pH}$ 8.0. Eluates were digested with 10 units of TEV protease (Invitrogen) on ice for $2 \mathrm{~h}$. Digested samples were diluted with IP/MS buffer and immunoprecipitated using anti-FLAG M2-agarose as above. IP/MS analysis was performed using Voyager DE STR (Applied Biosystems) as described previously (Fukumori et al., 2006).

$T N F \alpha$ in vitro proteolysis. The TNF $\alpha$ in vitro processing assay was performed as previously described (Fluhrer et al., 2008).

\section{Results}

PS1 is endoproteolytically cleaved at multiple sites

To investigate the mechanism of PS endoproteolysis, we generated a PS1 variant, which greatly facilitates the identification of the CTF upon endoproteolysis by mass spectrometry. Large parts of the cytoplasmic loop of PS1 are apparently functionally irrel- evant, as they can be deleted without major functional consequences (Saura et al., 2000). Therefore this domain can be used to insert protein tags. For example, we have previously introduced EGFP into the cytoplasmic loop to successfully study assembly and cell surface transport of fully functional PS $1 / \gamma$-secretase (Kaether et al., 2002). We now introduced a FLAG-tag after amino acid 321 of PS1 followed by a TEV-protease recognition site (PS1 FTEV) (Fig. 1A). Upon PS1 endoproteolysis, TEV-protease-mediated cleavage is expected to liberate small peptides, which can be isolated by immunoprecipitation via the FLAG epitope and subsequently investigated by mass spectrometry (Fig. $1 A)$. We first proved that such artificial PS1 variants are indeed physiologically fully functional. PS1 FTEV or PS1 wt were stably expressed in HEK293 cells stably coexpressing Swedish mutant APP. Western blot analysis revealed that both PS1 variants undergo endoproteolysis (Fig. $1 B)$. As expected PS1 NTFs of identical molecular weights were generated upon endoproteolysis. However, PS1 FTEV produced a CTF with the expected increase in its molecular weight (Fig. $1 B$ ). In addition, PS1 FTEV replaced (Thinakaran et al., 1996) the endogenous PS1 CTF, further suggesting that it behaved like PS1 wt in $\gamma$-secretase complex formation (Fig. $1 B)$. PS1 FTEV generated amounts of total $A \beta$ similar to those generated by wt PS1 (Fig. $1 B$ ), and mass-spectrometry analysis of the secreted $A \beta$ peptides showed that production of $\mathrm{A} \beta_{37}, \mathrm{~A} \beta_{38}, \mathrm{~A} \beta_{39}, \mathrm{~A} \beta_{40}$, and $\mathrm{A} \beta_{42}$ was unchanged in cells expressing PS1 FTEV compared to cells expressing PS1 wt (Fig. 1C). To further confirm that the $\gamma$-secretase activity observed for PS1 FTEV was specific for this variant and not due to interfering residual amounts of unreplaced endogenous PS, we analyzed whether PS1 FTEV was also functional in PS1/2 (PS ${ }^{-1-}$ ) double knock-out MEF cells. As shown in Figure $1 D$, PS1 FTEV was endoproteolysed and capable of restoring AICD and A $\beta$ production from the coexpressed APPsw-6myc substrate at levels similar to PS1 wt. Mass spectrometry of the secreted $\mathrm{A} \beta$ species demonstrated that PS1 FTEV generated the same profile of $\mathrm{A} \beta$ peptides, demonstrating that the observed activity was specific to the transfected PS1 FTEV (Fig. $1 E$ ). From these results, we conclude that PS1 FTEV is physiologically fully functional within the $\gamma$-secretase complex even in a cellular background, which is completely devoid of endogenous PS1 and PS2.

Mass spectrometry of the peptides liberated from the PS1 CTF by TEV protease revealed that the majority of CTFs begin with alanine 299 (Fig. 2A,B). Minor amounts of additional larger peptides were obtained reproducibly including those beginning with methionine 292, valine 293, leucine 295, valine 296, and methionine 298 (Fig. $2 A, B$ ). The major cleavage observed C-terminal of amino acid 298 (peptide starting with A299) is consistent with previous findings obtained by radio sequencing of the CTF derived from wt PS1 (Podlisny et al., 1997). No peptides were observed for a corresponding active site aspartate mutant (PS1 
A

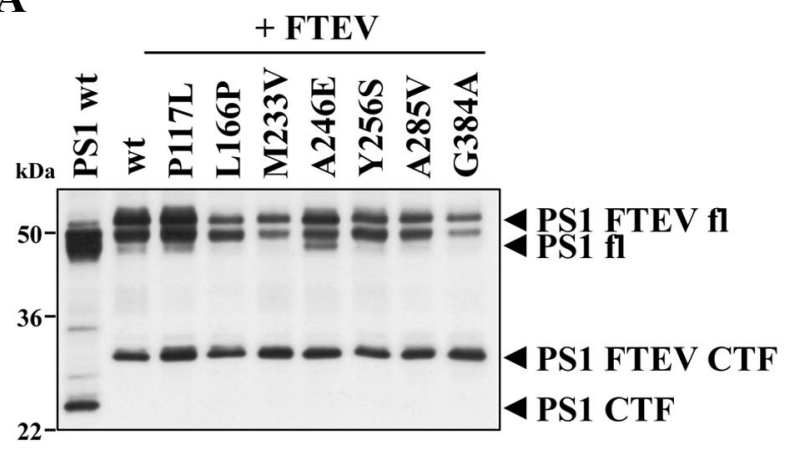

C

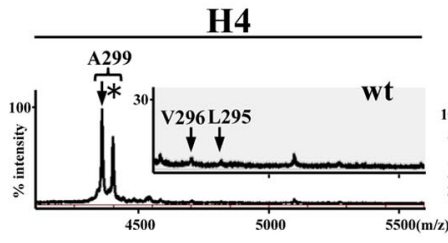

D
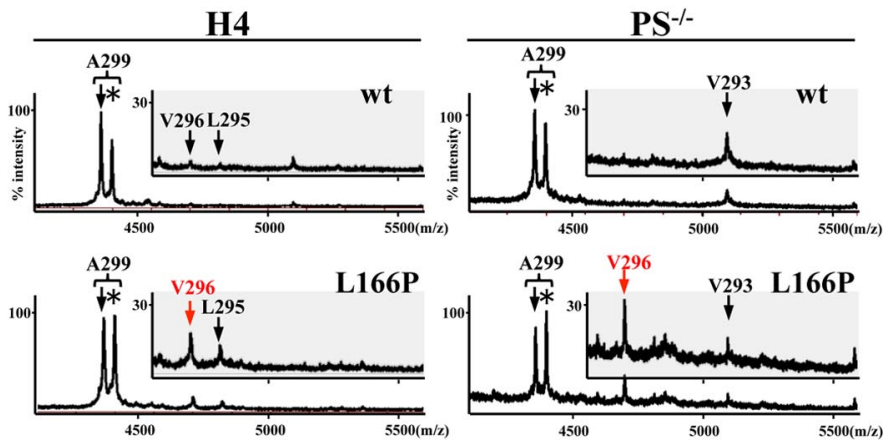

B
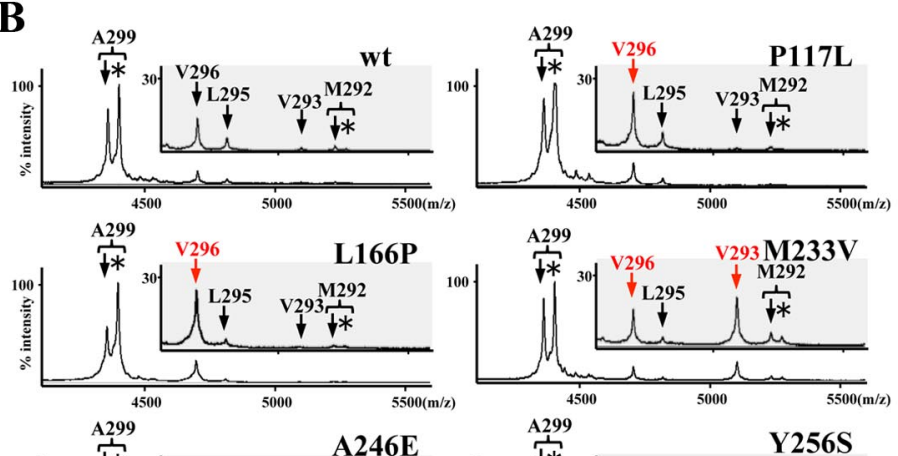

E

$293^{296}$

...QERNETLFPALIYSSTMVWLVNMAEG..

-FTEV

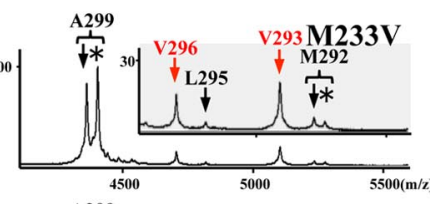

\begin{tabular}{|c|c|c|}
\hline & V296 & V293 \\
\hline P117L & $\boldsymbol{T}(1.9)$ & - \\
\hline L166P & $\boldsymbol{\uparrow}(2.1)$ & - \\
\hline M233V & $\boldsymbol{\uparrow}(1.2)$ & $\boldsymbol{\uparrow}(9.7)$ \\
\hline A246E & - & - \\
\hline Y256S & $\downarrow(0.2)$ & $\downarrow(0.2)$ \\
\hline A285V & - & - \\
\hline G384A & $\mathbf{4 ( 1 . 2 )}$ & - \\
\hline
\end{tabular}
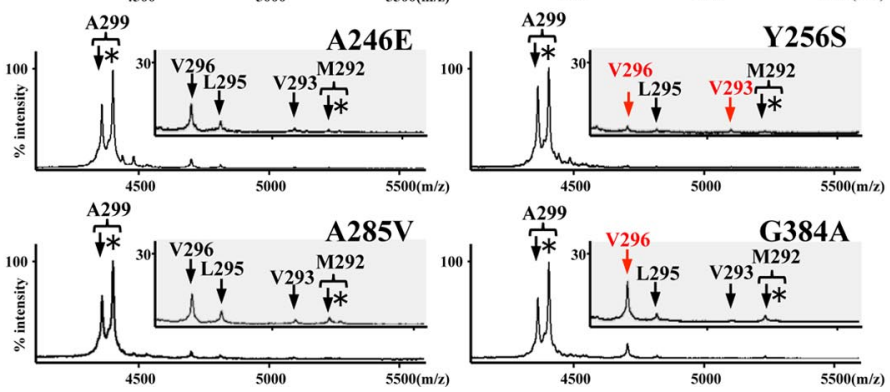

Figure 3. PS1 FAD mutants affect PS endoproteolysis. $A$, HEK293 cells stably expressing the indicated PS1 variants were analyzed for expression and PS endoproteolysis by immunoblotting of cell lysates as in Figure $1 B$. Note that wt and FAD mutant PS1 FTEV are endoproteolysed into larger CTFs that replace the endogenous PS1 CTF, demonstrating that the PS1 FTEV variants undergo functional $\gamma$-secretase complex formation. $\boldsymbol{B}$, Determination of the cleavage sites of PS1 FTEV in the presence or absence of FAD-associated mutations as described in Figure $2 A$. The intensity of the highest peak corresponding to endoproteolytic cleavage after position 298 (A299) was set to 100\%. Parts of the mass spectra are magnified (insets) to allow a better visualization of the V293 and V296 peaks. Note that the aggressive PS1 mutations P117L, L166P, M233V, Y256S, and G384A affect PS1 endoproteolysis at common sites (amino acid 293 or 296). C, H4 cells stably expressing wt or L166P mutant PS1 FTEV were analyzed for PS endoproteolysis cleavage sites as described in $\boldsymbol{B}$. Note that in H4 cells, cleavage at V296 and L295 is enhanced upon expression of the PS1 L166P mutant. $\boldsymbol{D}$, PS ${ }^{-1-}$ MEF cells transiently expressing wt or L166P mutant PS1 FTEV were analyzed for PS endoproteolysis cleavage sites as described in $\boldsymbol{B}$. $\boldsymbol{E}$, Summary of alterations in PS endoproteolysis caused by mutant PS1 variants. Changes in cleavage site usage of FAD mutants are denoted with red (V293, V296) arrowheads. Changes in cleavage site usage at positions V293 and V296 [increased $(\uparrow)$, decreased $(\downarrow)$, or unchanged $(-)$ ] are summarized in the table.

D385A) that served as negative control (Fig. $2 \mathrm{~A}$, bottom). We also confirmed the presence of CTFs starting at 292 and 293 that were identified as minor species (Podlisny et al., 1997). Furthermore, additional so far unknown cleavage sites between residues 291 and 298 were identified (Fig. 2B). Together these findings demonstrate multiple cleavages occurring within the hydrophobic domain encoded by exon 9 of PS1 (Fig. 2C).

FAD-associated PS1 mutations affect PS endoproteolysis FAD-associated PS1 and PS2 mutations cause a shift of the intramembrane $\gamma$-secretase cleavage, which in case of APP processing leads to enhanced $\mathrm{A} \beta_{42 / 43}$ generation (Haass, 2004). We now investigated whether such FAD-associated mutations affect the precision of PS1 endoproteolysis. We selected a spectrum of different FAD-associated PS1 mutations spread over the entire molecule and covering an age of disease onset ranging from very early (e.g., P117L, L166P, Y256S) to rather late (e.g., A246E, A285V). Mutant PS1 variants were expressed in HEK293 cells. Endoge- nous PS was replaced as expected as evident from the replacement of the endogenous PS1 CTF by the larger CTFs generated from the stably transfected wt and FAD mutant PS1 FTEV variants (Fig. 3A). All investigated FAD-associated PS1 mutations underwent endoproteolysis independent of the age of onset and the levels of $\mathrm{A} \beta_{42}$ produced (Fig. $3 A$ ). Mass-spectrometry analysis confirmed that all FAD-mutants showed the expected increased levels of $\mathrm{A} \beta_{42}$ or $\mathrm{A} \beta_{43}$ (data not shown) (Page et al., 2008), demonstrating that the introduction of the FTEV domain did not interfere with the pathogenic properties of the FAD mutants. Strikingly, aggressive FAD mutations affected PS1 endoproteolysis at common sites. Such mutations affected the relative production of PS1 CTF species beginning at amino acid 296 (P117L, L166P, G384A) or 293 and 296 (M233V, Y256S) (Fig. $3 B)$. No apparent changes in PS1 endoproteolysis were observed for the rather mild PS1 A246E and PS1 A285V mutations (Fig. $3 B)$. Enhanced formation of elongated PS1 CTF(s) beginning at 
A

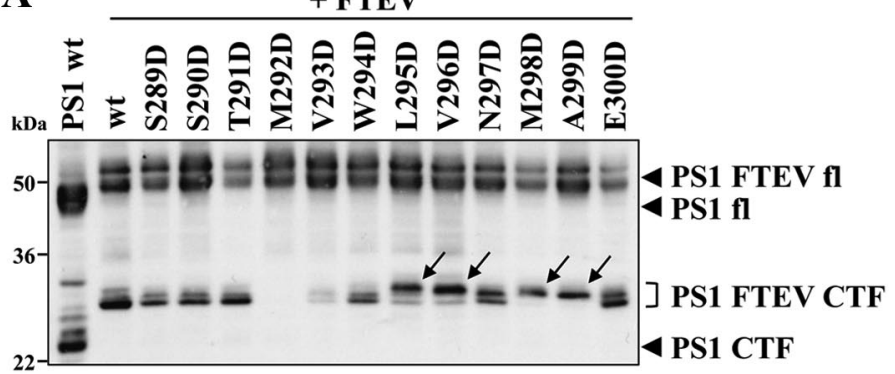

B
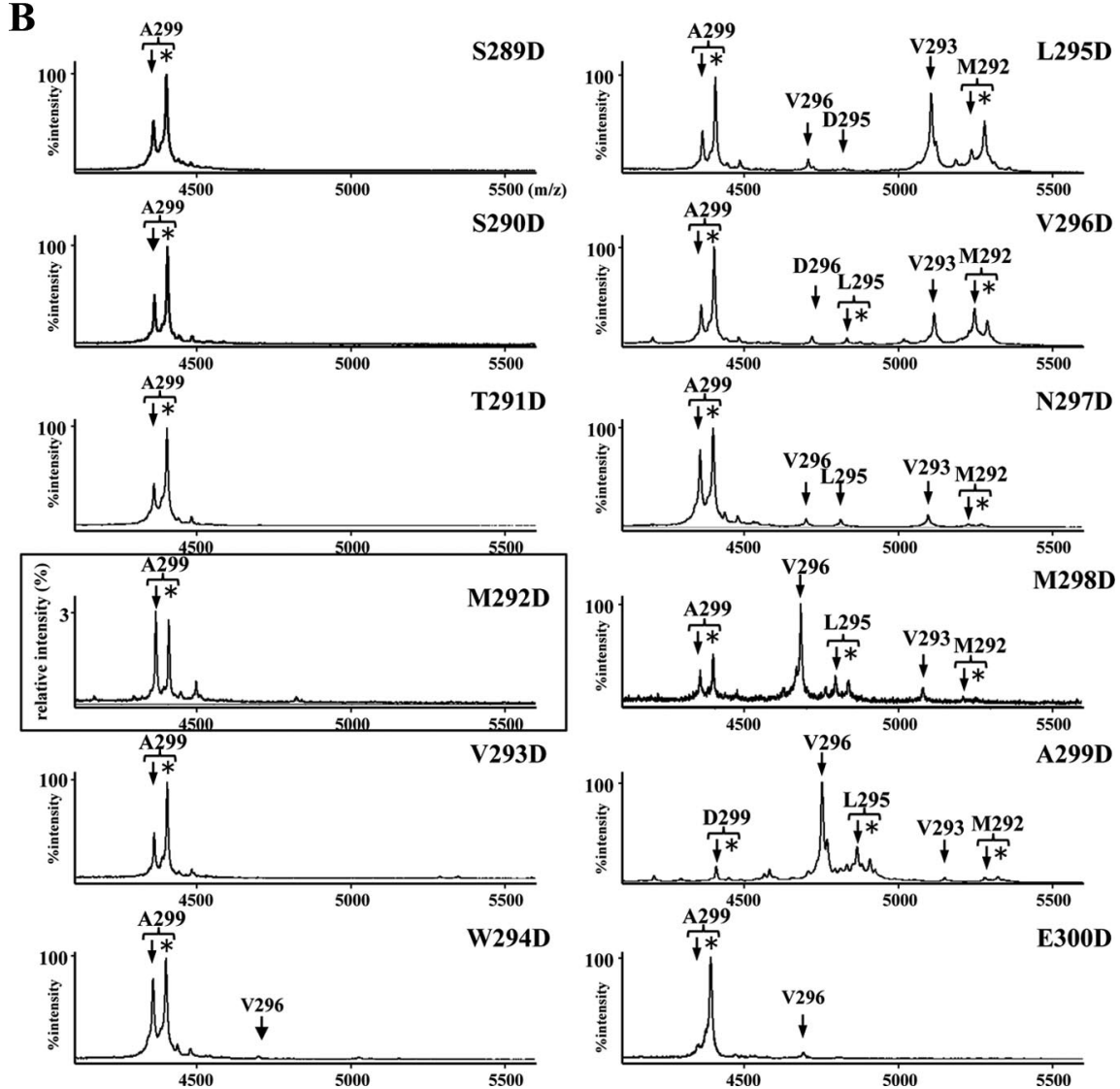

Figure 4. Stepwise endoproteolysis of presenilin. $\boldsymbol{A}$, Cell lysates from HEK293 cells stably expressing the indicated constructs were analyzed for PS expression and endoproteolysis by immunoblotting as in Figure $1 B$. Arrows indicate $M W$ shifts of the PS1 FTEV CTF observed for the L295D, V296D, M298D, and A299D mutants. B, Mass spectra of peptides derived from PS endoproteolysis of PS1 FTEV variants stably expressed in HEK293 cells as described in Figure $2 A$. The intensities of the highest peaks detected in the spectra were set to $100 \%$. Note that the high sensitivity of the MS analysis allowed the detection of an extremely weak A299 peak also for the M292D mutant (highlighted with the box), indicating very little residual PS autoproteolysis (note difference in scale).

amino acid 296 (and 295, respectively) was also observed in brain-derived neuroglioma $\mathrm{H} 4$ cells (Fig. $3 \mathrm{C}$ ) and upon expression of the PS1 L166P mutant in PS ${ }^{-1-}$ cells (Fig. 3D). From these findings, we conclude that aggressive PS1 mutations rather selectively affect endoproteolysis of PS1 after amino acid 296 or 293 (summarized in Fig. 3E).

PS1 endoproteolysis by $\gamma$-secretase-like $\varepsilon$-, $\zeta$-, and $\gamma$-cleavages

The above-described multiple cleavages are indicative for a stepwise cleavage similar to the $\varepsilon^{-}, \zeta^{-}$, and $\gamma$-cleavages described for intramembrane proteolysis of APP (Zhao et al., 2004; QiTakahara et al., 2005; Takami et al., 2009) [summarized by Haass and Selkoe (2007) and Steiner et al. (2008)]. Previously, we demonstrated that the insertion of a negatively charged amino acid at position 292 prevents PS1 endoproteolysis (Steiner et al., 1999a). To further prove such a multiple cleavage mechanism, we systematically exchanged the amino acids from position 289 to 300 with aspartate residues. This revealed that only aspartate residues at amino acids 292 and 293 significantly reduced endoproteolysis, whereas all other exchanges still allowed endoproteolysis to occur (Fig. 4A). Since these mutant PS variants are fully active in terms of $\gamma$-secretase activity (data not shown), these data further confirm that noncleavable PS1 variants can support $\gamma$-secretase activity (Steiner et al., 1999b). Whereas the V293D showed residual cleavage activity, the M292D mutant blocked PS endoproteolysis as expected from our previous results (Steiner et al., 1999b). Based on the negative charge introduced, the lack of endoproteolysis of the M292D mutation suggests that this residue may be required to insert into the catalytically active site (see model described in Discussion). In contrast, aspartate residues at amino acids 295, 296, 298, and 299 allowed efficient endoproteolysis but resulted in the generation of significantly elevated levels of elongated PS1 CTFs, which could be discriminated by their aberrant migration in SDS-PAGE (Fig. 4A). However, no such increase was observed for the N297D and the E300D mutation. Mass spectrometry of PS1 CTFs revealed that the introduction of aspartate residues at amino acids 295 and 296 caused a significant increase of PS1 CTFs beginning at positions 293 and 292 (Fig. $4 B$ ). Moreover, aspartate residues at positions 298 and 299 selectively enhanced PS1 CTFs beginning at amino acid 296 and severely lowered the cleavage at amino acid 299 (Fig. 4B). In contrast, an aspartate residue at amino acid 300 had no effect on endoproteolysis and allows the production of the native PS1 CTF beginning with amino acid 299 (Fig. 4B). Likewise, aspartate substitutions of the N-terminal residues 289 , 290, and 291 as well as of residue 294 did not change the sequence of the PS1 CTFs generated (Fig. 4B). Therefore it appears that aspartate residues at amino acids 295 and 296 as well as mutations at amino acids 298 and 299 partially arrest endoproteolysis at intermediate processing steps. Cleavage sites at 292/293, 296, and 299 are separated by roughly 3 amino acids each, suggesting a very similar spacing of intermediate cuts as observed for the $\varepsilon$-, $\zeta$-, and $\gamma$-secretase cleavage of APP (Zhao et al., 2004; QiTakahara et al., 2005; Takami et al., 2009). Such multiple and equally spaced cleavages are further supported by the introduction of double aspartate mutations (PS1 L295D/A299D and V296D/A299D) (Fig. 5A). Like the corresponding single aspar- 
A
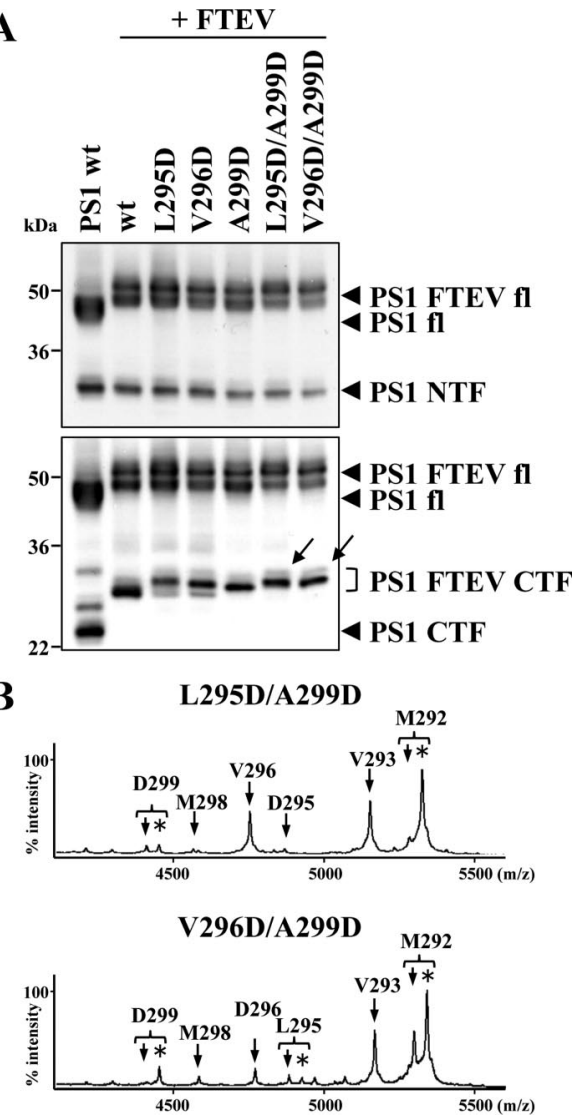

Figure 5. Double aspartate mutations arrest endoproteolysis at the initial cleavage site. $A$, Cell lysates from HEK293 cells stably expressing the indicated PS1 FTEV constructs were analyzed for PS expression and endoproteolysis by immunoblotting as in Figure 1 B. B. Mass spectra of peptides derived from PS endoproteolysis of PS1 FTEV variants stably expressed in HEK293 cells as described in Figure 2A. The intensities of the highest peaks observed in the spectra corresponding to endoproteolytic cleavage after position 291 (M292) were set to 100\%. Note that double aspartate mutants arrest endoproteolytic cleavage at residue 292. Arrows indicate reduced migration of PS1 CTFs derived from L295D/A299D and V296D/A299D.

tate mutations, the double mutants PS1 L295D/A299D and V296D/A299D did not affect $\gamma$-secretase function (data not shown). Both double mutations apparently arrested endoproteolysis to a significant portion at amino acids 292/293 and did not allow the cleavage to proceed to the final cleavage site at amino acid 299 (Fig. 5B).

\section{Mutations close to the critical D385 residue affect the catalytic properties of the GxGD motif without interfering with endoproteolysis}

Previously, we demonstrated that several mutations within the GxGD active site motif such as the PS1 G384I, G384P, and G384W mutations surprisingly lead to a loss of $\gamma$-secretase function, although PS1 endoproteolysis is not affected (Steiner et al., 2000) (see also Fig. 6A). To identify the mechanism that allows their endoproteolysis, we reinvestigated these mutations and analyzed endoproteolysis by mass spectrometry. This revealed that the PS1 mutations G384I and G384P arrested endoproteolysis at the intermediate cleavage sites 296 and 295 and reduced the final cleavage at amino acid 299 (Fig. 6B). The third mutation, PS1 G384W, almost completely arrested endoproteolysis at the initial cleavage site at amino acid 292 (Fig. 6B). These findings therefore demonstrate that this class of rather surprising mutations, which do allow endoproteolysis but abolish substrate cleavage, result in a tremendous alteration in the use of the above-identified cleavage sites, further supporting the hypothesis that PS cleavage occurs by stepwise autoproteolysis. This finding also raises the question of whether the loss of $\gamma$-secretase function is associated with a miscleavage of PS1 induced by the PS1 G384 mutations. To address this question, we introduced the G384P mutation into PS1 $\Delta$ exon9, which does not undergo endoproteolysis due to the deletion of the exon 9-encoded cleavage site domain, but which is functional with respect to APP substrate cleavage (Thinakaran et al., 1996). Assessment of APP processing in PS ${ }^{-1-}$ cells demonstrated that the PS1 $\Delta$ exon9/G384P double mutant failed to cleave APP in the absence of PS endoproteolysis (Fig. 6C). In agreement with our previous results (Steiner et al., 2000), the PS1 G384P single mutant inhibited substrate cleavage but maintained PS endoproteolysis (Fig. 6C). To additionally and finally exclude that miscleavage and loss of substrate processing are connected, we introduced the PS1 G384A and PS1 G384P mutations into the functionally conserved GxGD motif of the signal peptide peptidase like protease SPPL2b (Krawitz et al., 2005; Fluhrer et al., 2008) (generating SPPL2b G420A and G420P), which mediates stepwise $\varepsilon^{-}, \zeta^{-}$, and $\gamma$-like intramembrane proteolysis of tumor necrosis factor $\alpha$ (TNF $\alpha$ ) (Fluhrer et al., 2006, 2009). Since SPPL2b does not undergo endoproteolysis, but is proteolytically active as a full-length protein (Fluhrer et al., 2009), this allowed us to independently investigate the effect of this mutation in the absence of autoproteolysis. As previously reported (Fluhrer et al., 2008), we evaluated SPPL2b activity in a time course experiment. Membranes of HEK293 cells expressing the SPPL2b variants (Fig. $6 D)$ and $\mathrm{TNF} \alpha$ were incubated for the indicated time points, and formation of the intracellular domain (ICD) was monitored. Consistent with our previous findings (Fluhrer et al., 2008), wt SPPL2b initiated intramembrane proteolysis of TNF $\alpha$ with the generation of a peptide designated ICD1 in Figure $6 D$. This peptide was then rapidly processed via intermediates (ICD2/3) to the final ICD4 product (Fig. 6D). Processing of ICD1 by SPPL2b G420A was slowed as reported previously (Fluhrer et al., 2008), indicating a partial loss of function (Fig. 6D). SPPL2b G420P caused a much stronger, severe loss of function, since production of the ICDs was slowed to a much greater extent (Fig. 6D). This is further supported by a significantly stronger accumulation during all time points of the direct SPPL2b substrate (TNF $\alpha$ NTF) (Fig. 6D) in SPPL2b G420P-expressing cells compared to cells expressing SPPL2b G420A. Since SPPL2b, like all other SPP family members, does not require endoproteolysis for its function (Fluhrer et al., 2009), this finding further supports the conclusion that the loss of function induced by the PS1 G384P mutation is unrelated to changes in autoproteolysis but is rather due to inhibition of substrate cleavage. Thus a residual very low catalytic activity of PS1 G384P (as observed in the analogous SPPL2b G420P mutation) is apparently still sufficient to allow PS endoproteolysis suggesting that the exon 9-encoded domain is an optimal substrate for PS1-mediated intramembrane proteolysis.

\section{Discussion}

Although endoproteolysis is a well known evolutionary conserved feature of all PSs and was already described by Thinakaran et al. in a pivotal publication in 1996 (Thinakaran et al., 1996), very little is still known about its molecular mechanisms. We now present further evidence that endoproteolysis occurs by autoproteolysis and not by an independent protease. This is demonstrated by the finding that FAD-associated PS mutations as well as other engineered mutations can affect the precision of PS endoproteolysis. Moreover, particularly pathologically aggressive mu- 
A

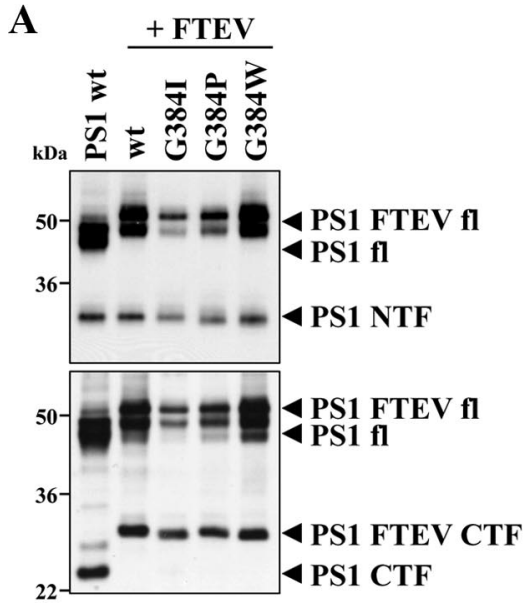

C

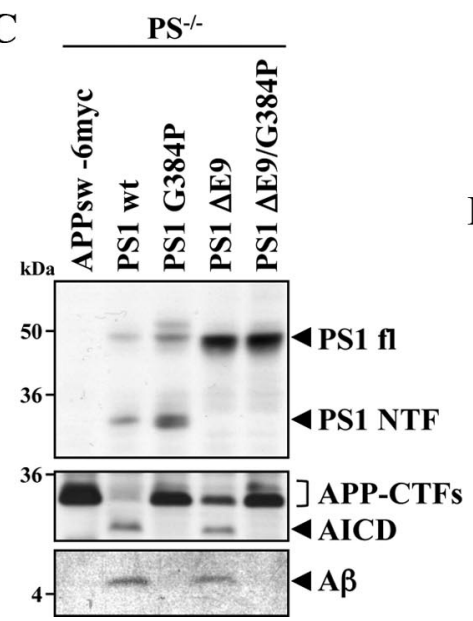

D
B
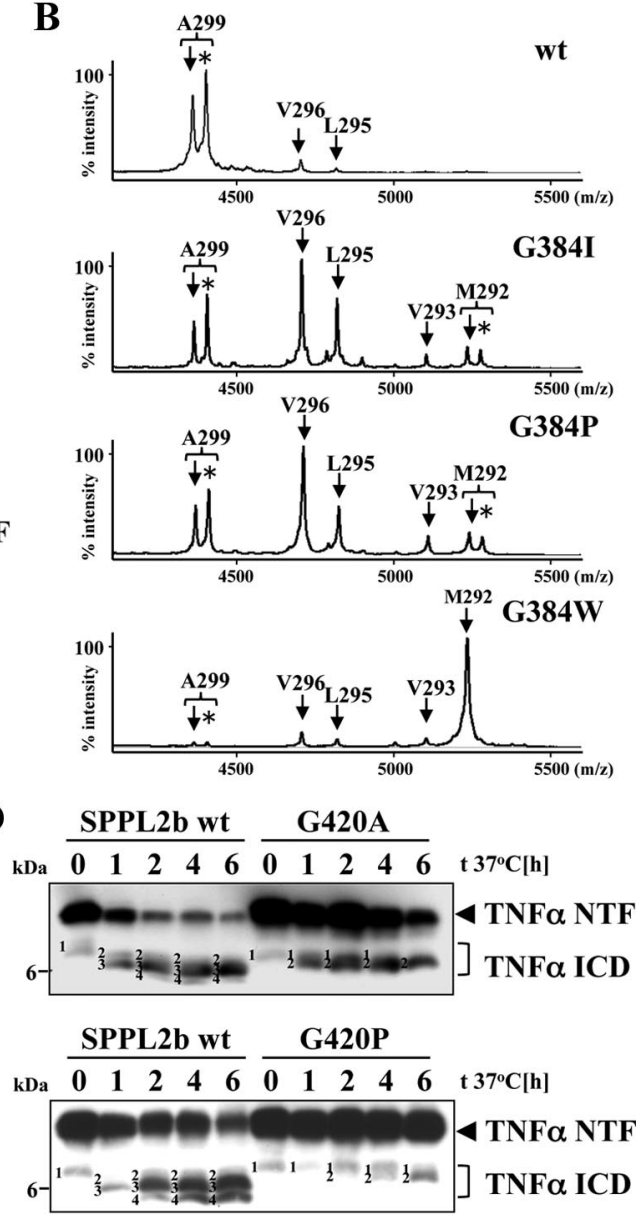

Figure 6. PS1 mutants that support PS endoproteolysis but not $\gamma$-secretase cleavage of APP affect the catalytic domain. $A$, Cell lysates from HEK293 cells stably expressing the indicated PS1 constructs were analyzed for PS expression and endoproteolysis by immunoblotting as in Figure $1 B$. B, Mass spectra of peptides derived from PS endoproteolysis of PS1 FTEV variants stably expressed in HEK293 cells as described in Figure $2 A$. The intensities of the highest peaks observed in the respective spectra were set to $100 \%$. Note that glycine mutants arrest endoproteolytic cleavage at residue 292 or 295/296. C, PS endoproteolysis of the indicated mutant PS1 constructs containing the exon 9 deletion and/or the G384P mutation and APP processing were analyzed as in Figure $1 D$. $D$, Conversion of the TNF $\alpha$ ICD is slowed by the SPPL2b G420A mutation and severely reduced by the SPPL2b G420P mutation. Membranes of HEK 293 cells expressing wt SPPL2b and the indicated SPPL2b variants and TNF $\alpha$ were incubated for the indicated time points at $37^{\circ} \mathrm{C}$ and formation of the intracellular domain (ICD) was monitored by immunoblotting using the anti FLAG M2 antibody. Note that improvement of the in vitro assays allowed the additional detection of ICD4 (Fluhrer et al., 2008).

tations with a very early age of onset cause robust changes in endoproteolysis of PS. Similar to the effects on processing of the APP substrate, most mutations increase the production of elongated cleavage products, i.e., elongated PS CTFs. This direct effect on endoproteolysis is most readily explained by effects of the PS1 mutations on their own processing via autoproteolysis. As discussed for the effects of PS1 mutations on APP processing (Haass, 2004), these mutants apparently influence the structure of PS particularly around the catalytic center, which then leads to miscleavages.

Mechanistically, three different scenarios could be envisioned for PS endoproteolysis. First, the cleavage site domain in the PS loop is cleaved only once but different cleavage sites are used in each molecule thereby generating the observed heterogeneity of the CTFs. Second, cleavage occurs in a sequential manner from M292-A299 i.e., from $\mathrm{N}$ to $\mathrm{C}$ terminus in type 2 orientation of the cleavage site domain or third, in sequential manner but in opposite direction in type 1 orientation, i.e., from $\mathrm{C}$ to $\mathrm{N}$ terminus. As outlined in the following, our data suggest that PS endoproteoly- sis is likely to occur in a stepwise manner, very similar to that proposed for the intramembrane proteolysis of APP, Notch, and other substrates (Steiner et al., 2008). For $\gamma$-secretase substrates, an $\varepsilon^{-}$, $\zeta^{-}$, and $\gamma$ - cleavage is discussed to occur in a stepwise manner starting with a cleavage at the $\varepsilon$-site (Sastre et al., 2001; Weidemann et al., 2002; Qi-Takahara et al., 2005). Apparently, these cleavages are separated by $\sim 3$ amino acids (Qi-Takahara et al., 2005; Takami et al., 2009). In line with these findings, we found that the endoproteolytic cuts of PS itself are also roughly spaced by 3 amino acids, indicating that the PS cleavage site domain might be in a loose $\alpha$-helical conformation, consistent with previous results (Knappenberger et al., 2004). This characteristic and consistent tripeptide-like spacing of cleavages seems to argue against the alternative possibility that PS mutations may cause different coexisting conformations that are cleaved only once at different sites and not sequentially. Moreover, all FAD and synthetic mutants for which changes in PS endoproteolysis site usage have been observed cause these changes at cleavage sites $\mathrm{N}$-terminal to the major cleavage site at A299. This finding is most readily explained by a sequentially occurring cleavage in type 2 orientation and seems unlikely to support cleavage of the PS loop substrate in the opposite type 1 orientation. Finally, an involvement of aminopeptidases to generate CTFs with A299 as major site also seems unlikely, given that several mutations (including even the G384W mutation, which is far away from the cleavage site) cause the accumulation of longer CTFs. Unfortunately the kinetics of PS endoproteolysis cannot be investigated by pulse chase experiments due to the extremely long half-life time of the $\gamma$-secretase complex (Thinakaran et al., 1996). However, time course experiments fully confirmed sequential cleavage by the related SPPL2b (Fluhrer et al., 2008). Our findings thus suggest that endoproteolysis is very likely initiated by an $\varepsilon$-like cleavage similar to e.g., APP substrate cleavage. This cleavage may then be followed by a $\zeta$-like cleavage that occurs at amino acids 295/296 in the middle of the initial and final cuts, respectively (summarized in Fig. 7A). Consecutive processing may then culminate in the $\gamma$-like cleavage, which generates the $\mathrm{N}$ terminus of the PS1 CTF beginning with alanine 299. The latter is the final cleavage of the stepwise processing mechanism and consequently accumulates in vivo, which is consistent with previous findings (Podlisny et al., 1997). Thus, PS apparently processes itself in a manner very similar to APP or other substrates. Moreover, rather unusual mutations such as PS1 G384I/P/W, which allow normal endoproteolysis but not $\gamma$-secretase substrate cleavage selectively arrest processing at $\varepsilon$-, or $\zeta$-like cleavage sites giving rise to miscleaved CTFs. Again, these findings are in agreement with PS autoproteolysis. This conclusion is consistent with the observa- 
tion that reconstitution of $\gamma$-secretase activity in yeast not only allows substrate processing but also initiates PS endoproteolysis as soon as all four critically required components are coexpressed (Edbauer et al., 2003). Moreover, we found that all cleavages reported in this manuscript, including the newly identified cleavages, are dependent on the presence of the catalytic aspartate residues. In addition, certain $\gamma$-secretase inhibitors can apparently reduce endoproteolysis (Beher et al., 2001; Campbell et al., 2002). Together, these observations provide conclusive evidence that PS is a zymogene that indeed undergoes autoproteolysis as suggested previously.

If PS is generated as a zymogene-like precursor, endoproteolysis of PS should have immediate functional consequences for $\gamma$-secretase activity. Our findings support the idea that PS endoproteolysis is required to convert full-length PS into a biologically active derivative capable of intramembrane proteolysis of type 1-oriented membrane protein substrates. Such an activating process needs to be discriminated from the initial proteolytic activity of full-length PS, which is obviously sufficient to process itself.

How do cleavage affecting mutations fit in a zymogene paradigm, specifically those that allow full $\gamma$-secretase activity in the absence of any endoproteolysis and vice versa? Here we must discriminate four types of mutations with different effects on activity (Fig. 7B):

(1) The PS1 $\Delta$ exon9 mutation does not allow endoproteolysis, because the cleavage site domain is missing. However, this mutation still allows substrate processing. Apparently the lack of the hydrophobic domain is sufficient to remove a putative hydrophobic "plug" from $\gamma$-secretase (see below), which prevents substrate access and processing.

(2) The M292D mutation prevents endoproteolysis, but similarly to the PS1 $\Delta$ exon9 mutation, fully supports $\gamma$-secretase activity. The negative charge introduced at this site may interfere with the hydrophobicity of the cleavage site domain or the hydrophobic TM domains surrounding it and thus affect its ability to "dive" into the active site-containing pore of $\gamma$-secretase.

(3) Some mutations close to the catalytically required aspartate 385, such as the PS1 G384P mutation, support endoproteolysis but surprisingly fail to allow $\gamma$-secretase substrate processing. Apparently they harbor a residual very low $\gamma$-secretase activity, which is insufficient to support type 1 substrate processing but is still sufficient to allow endoproteolysis to occur. This might be explained by the fact that the access to the protease active site is different for the hydrophobic cleavage site domain in the PS loop than for type 1 substrates (Fig. 7C). Whereas the loop can freely enter the catalytic pore/cavity from the cytosol, type 1 substrates access the active site laterally. The lateral access of sub- strates to the catalytic aspartates might be constrained by certain amino acids, such as proline and others at amino acid 384 (Steiner et al., 2000). We now show that these mutants not only have an impact on type 1 substrate cleavage but also display a severe loss of function in the precision of PS endoproteolysis by arresting endoproteolysis at intermediate processing steps. The finding that the analogous glycine-to-proline mutation blocks substrate cleavage of the PS-related SPPL2b, which does not undergo endoproteolysis, shows that the block of substrate cleavage of PS1 G384P is uncoupled from its effects on endoproteolysis. This is fully supported by the observation that the PS1 $\Delta$ exon9 G384P mutant is also inactive in terms of substrate processing.

Interestingly, several mutants were also identified at Y288 close to the cleavage site domain, which are capable of substantial PS endoproteolysis but not substrate cleavage (Laudon et al., 2004; Zhao et al., 2008). One such mutant, PS1 Y288N, also par- 
tially arrested endoproteolysis at an intermediate processing step (data not shown).

(4) Some PS mutations, such as the mutations of the two catalytically required aspartate residues as well as, e.g., mutants of the GxGD (Steiner et al., 2000; Pérez-Revuelta et al., 2010) and PAL motifs (Wang et al., 2004, 2006; Nakaya et al., 2005) of the active site and certain mutations within the exon 8-encoded domain, are complete or severe loss-of-function mutations, strongly reducing or even totally preventing endoproteolysis and substrate cleavage (Laudon et al., 2004; Nakaya et al., 2005). Lack of the catalytically required aspartate residues is an obvious cause for such a failure. Other PS mutations may severely affect PS structure, rendering it into a biologically inactive conformation, which, however, still allows $\gamma$-secretase complex assembly.

Our findings together with previous observations (Thinakaran et al., 1996; Podlisny et al., 1997; Steiner et al., 1999b; Knappenberger et al., 2004) fit into the following model. A fully assembled immature $\gamma$-secretase complex consists of full-length PS, immature NCT, APH-1, and PEN-2 (Haass, 2004). In such a complex, the hydrophobic cleavage site domain encoded within exon 9 must have access to the active site, probably formed by a pore- or cavity-like structure (Sato et al., 2006; Tolia et al., 2006; Li et al., 2009; Osenkowski et al., 2009). In contrast to $\gamma$-secretase substrates, which have lateral access to the active center, the cleavage site domain must interact with the catalytic center by diving into a pore or cavity (Fig. $7 C$ ), which had been proposed by electron microscopy (Osenkowski et al., 2009), cysteine scanning (Sato et al., 2006; Tolia et al., 2006), and chemical cross-linking (Tolia et al., 2008). Upon diving in, the active site is blocked for lateral access of $\gamma$-secretase substrates, and the complex is therefore in a "closed" configuration (Fig. 7C). Substrates can only gain access when the "plug" has been removed by autoproteolysis and an "open" conformation has been adopted (Fig. 7C). Consistent with this model is the finding that an exon 9-encoding peptide blocks $\gamma$-secretase activity by competing with substrates for access to the catalytic pore (Knappenberger et al., 2004) (and data not shown). Similarly to intramembrane proteolysis of $\gamma$-secretase substrates, sequential processing is then required to remove a considerable part of the cleavage site domain, which represents the intrinsic substrate for autoproteolysis (Fig. 7A). This may, as in the case of natural substrates, allow full liberation of the exon 9-encoded domain and release of both ends from the active site pore structure (Fig. 7C). If the initial cleavage site at amino acids 292/293 is mutagenized to aspartate residues, interaction with the hydrophobic TM domains of the catalytically active site may be prohibited by the insertion of negative charges at these two residues. Thus, such a mutant cleavage site domain would be expected to be expelled from the catalytic center if one considers that close hydrophobic interactions with the active site-containing TMDs 6 and 7 surrounding the water accessible cavity are required (Fig. 7B) (Sato et al., 2006; Tolia et al., 2006). This model is supported by the finding that peptides derived from the exon 9 domain containing the M292D mutation fail to block $\gamma$-secretase activity (Knappenberger et al., 2004). As discussed above, this model may also predict that the cleavage site domain is processed in a type 2 orientation (i.e., endoproteolytic cleavage proceeds in direction from the $\mathrm{N}$ to the $\mathrm{C}$ terminus), a hypothesis that may be supported by our finding that FAD-associated PS1 mutations rather affect the $\varepsilon^{-}$, and $\zeta$-like cleavage instead of the $\gamma$-like cleavage. This is quite surprising, since GxGD proteases appear to discriminate between type 1- and type 2-oriented substrates (Steiner et al., 2008; Fluhrer et al., 2009). So far $\gamma$-secretase has been known to exclusively process type 1-oriented substrates, whereas mem- bers of the SPP and SPPL family process type 2-oriented proteins. Moreover, our findings demonstrate that PS-mediated autoproteolysis occurs without an initiating cleavage, which is thought to be required for regulated intramembrane proteolysis by $\gamma$-secretase (Struhl and Adachi, 2000; Steiner et al., 2008).

\section{References}

Beher D, Wrigley JD, Nadin A, Evin G, Masters CL, Harrison T, Castro JL, Shearman MS (2001) Pharmacological knock-down of the presenilin 1 heterodimer by a novel $\gamma$-secretase inhibitor: implications for presenilin biology. J Biol Chem 276:45394-45402.

Campbell WA, Iskandar MK, Reed ML, Xia W (2002) Endoproteolysis of presenilin in vitro: inhibition by gamma-secretase inhibitors. Biochemistry 41:3372-3379.

Campbell WA, Reed ML, Strahle J, Wolfe MS, Xia W (2003) Presenilin endoproteolysis mediated by an aspartyl protease activity pharmacologically distinct from gamma-secretase. J Neurochem 85:1563-1574.

Capell A, Saffrich R, Olivo JC, Meyn L, Walter J, Grünberg J, Mathews P, Nixon R, Dotti C, Haass C (1997) Cellular expression and proteolytic processing of presenilin proteins is developmentally regulated during neuronal differentiation. J Neurochem 69:2432-2440.

Capell A, Grünberg J, Pesold B, Diehlmann A, Citron M, Nixon R, Beyreuther K, Selkoe DJ, Haass C (1998) The proteolytic fragments of the Alzheimer's disease-associated presenilin-1 form heterodimers and occur as a 100-150-kDa molecular mass complex. J Biol Chem 273:3205-3211.

Edbauer D, Winkler E, Regula JT, Pesold B, Steiner H, Haass C (2003) Reconstitution of gamma-secretase activity. Nat Cell Biol 5:486-488.

Fluhrer R, Grammer G, Israel L, Condron MM, Haffner C, Friedmann E, Böhland C, Imhof A, Martoglio B, Teplow DB, Haass C (2006) A gamma-secretase-like intramembrane cleavage of TNFalpha by the GxGD aspartyl protease SPPL2b. Nat Cell Biol 8:894-896.

Fluhrer R, Fukumori A, Martin L, Grammer G, Haug-Kröper M, Klier B, Winkler E, Kremmer E, Condron MM, Teplow DB, Steiner H, Haass C (2008) Intramembrane proteolysis of GXGD-type aspartyl proteases is slowed by a familial Alzheimer disease-like mutation. J Biol Chem 283:30121-30128.

Fluhrer R, Steiner H, Haass C (2009) Intramembrane proteolysis by signal peptide peptidases: a comparative discussion of GXGD-type aspartyl proteases. J Biol Chem 284:13975-13979.

Fukumori A, Okochi M, Tagami S, Jiang J, Itoh N, Nakayama T, Yanagida K, Ishizuka-Katsura Y, Morihara T, Kamino K, Tanaka T, Kudo T, Tanii H, Ikuta A, Haass C, Takeda M (2006) Presenilin-dependent gammasecretase on plasma membrane and endosomes is functionally distinct. Biochemistry 45:4907-4914.

Haass C (2004) Take five-BACE and the gamma-secretase quartet conduct Alzheimer's amyloid beta-peptide generation. EMBO J 23:483-488.

Haass C, Selkoe DJ (2007) Soluble protein oligomers in neurodegeneration: lessons from the Alzheimer's amyloid beta-peptide. Nat Rev Mol Cell Biol 8:101-112.

Herreman A, Hartmann D, Annaert W, Saftig P, Craessaerts K, Serneels L, Umans L, Schrijvers V, Checler F, Vanderstichele H, Baekelandt V, Dressel R, Cupers P, Huylebroeck D, Zwijsen A, Van Leuven F, De Strooper B (1999) Presenilin 2 deficiency causes a mild pulmonary phenotype and no changes in amyloid precursor protein processing but enhances the embryonic lethal phenotype of presenilin 1 deficiency. Proc Natl Acad Sci U S A 96:11872-11877.

Jacobsen H, Reinhardt D, Brockhaus M, Bur D, Kocyba C, Kurt H, Grim MG, Baumeister R, Loetscher H (1999) The influence of endoproteolytic processing of familial Alzheimer's disease presenilin 2 on abeta42 amyloid peptide formation. J Biol Chem 274:35233-35239.

Kaether C, Lammich S, Edbauer D, Ertl M, Rietdorf J, Capell A, Steiner H, Haass C (2002) Presenilin-1 affects trafficking and processing of betaAPP and is targeted in a complex with nicastrin to the plasma membrane. J Cell Biol 158:551-561.

Knappenberger KS, Tian G, Ye X, Sobotka-Briner C, Ghanekar SV, Greenberg BD, Scott CW (2004) Mechanism of gamma-secretase cleavage activation: is gamma-secretase regulated through autoinhibition involving the presenilin-1 exon 9 loop? Biochemistry 43:6208-6218.

Krawitz P, Haffner C, Fluhrer R, Steiner H, Schmid B, Haass C (2005) Differential localization and identification of a critical aspartate suggest nonredundant proteolytic functions of the presenilin homologues SPPL2b and SPPL3. J Biol Chem 280:39515-39523. 
Laudon H, Karlström H, Mathews PM, Farmery MR, Gandy SE, Lundkvist J, Lendahl U, Näslund J (2004) Functional domains in presenilin 1: the Tyr-288 residue controls gamma-secretase activity and endoproteolysis. J Biol Chem 279:23925-23932.

Li H, Wolfe MS, Selkoe DJ (2009) Toward structural elucidation of the gamma-secretase complex. Structure 17:326-334.

Moehlmann T, Winkler E, Xia X, Edbauer D, Murrell J, Capell A, Kaether C, Zheng H, Ghetti B, Haass C, Steiner H (2002) Presenilin-1 mutations of leucine 166 equally affect the generation of the Notch and APP intracellular domains independent of their effect on Abeta 42 production. Proc Natl Acad Sci U S A 99:8025-8030.

Nakaya Y, Yamane T, Shiraishi H, Wang HQ, Matsubara E, Sato T, Dolios G, Wang R, De Strooper B, Shoji M, Komano H, Yanagisawa K, Ihara Y, Fraser P, St George-Hyslop P, Nishimura M (2005) Random mutagenesis of presenilin-1 identifies novel mutants exclusively generating long amyloid beta-peptides. J Biol Chem 280:19070-19077.

Nyabi O, Bentahir M, Horré K, Herreman A, Gottardi-Littell N, Van Broeckhoven C, Merchiers P, Spittaels K, Annaert W, De Strooper B (2003) Presenilins mutated at Asp-257 or Asp-385 restore Pen-2 expression and Nicastrin glycosylation but remain catalytically inactive in the absence of wild type Presenilin. J Biol Chem 278:43430-43436.

Osenkowski P, Li H, Ye W, Li D, Aeschbach L, Fraering PC, Wolfe MS, Selkoe DJ, Li H (2009) Cryoelectron microscopy structure of purified gammasecretase at 12 A resolution. J Mol Biol 385:642-652.

Page RM, Baumann K, Tomioka M, Pérez-Revuelta BI, Fukumori A, Jacobsen H, Flohr A, Luebbers T, Ozmen L, Steiner H, Haass C (2008) Generation of Abeta38 and Abeta42 is independently and differentially affected by familial Alzheimer disease-associated presenilin mutations and gammasecretase modulation. J Biol Chem 283:677-683.

Pérez-Revuelta BI, Fukumori A, Lammich S, Yamasaki A, Haass C, Steiner H (2010) Requirement for small side chain residues within the GxGDmotif of presenilin for gamma-secretase substrate cleavage. J Neurochem 112:940-950.

Podlisny MB, Citron M, Amarante P, Sherrington R, Xia W, Zhang J, Diehl T, Levesque G, Fraser P, Haass C, Koo EH, Seubert P, St George-Hyslop P, Teplow DB, Selkoe DJ (1997) Presenilin proteins undergo heterogeneous endoproteolysis between Thr291 and Ala299 and occur as stable $\mathrm{N}$ - and C-terminal fragments in normal and Alzheimer brain tissue. Neurobiol Dis 3:325-337.

Qi-Takahara Y, Morishima-Kawashima M, Tanimura Y, Dolios G, Hirotani N, Horikoshi Y, Kametani F, Maeda M, Saido TC, Wang R, Ihara Y (2005) Longer forms of amyloid $\beta$ protein: implications for the mechanism of intramembrane cleavage by $\gamma$-secretase. J Neurosci 25:436-445.

Sastre M, Steiner H, Fuchs K, Capell A, Multhaup G, Condron MM, Teplow DB, Haass C (2001) Presenilin-dependent gamma-secretase processing of beta-amyloid precursor protein at a site corresponding to the $\mathrm{S} 3$ cleavage of Notch. EMBO Rep 2:835-841.

Sato C, Morohashi Y, Tomita T, Iwatsubo T (2006) Structure of the catalytic pore of $\gamma$-secretase probed by the accessibility of substituted cysteines. J Neurosci 26:12081-12088.

Saura CA, Tomita T, Soriano S, Takahashi M, Leem JY, Honda T, Koo EH, Iwatsubo T, Thinakaran G (2000) The nonconserved hydrophilic loop domain of presenilin (PS) is not required for PS endoproteolysis or enhanced abeta 42 production mediated by familial early onset Alzheimer's disease-linked PS variants. J Biol Chem 275:17136-17142.

Shirotani K, Takahashi K, Ozawa K, Kunishita T, Tabira T (1997) Determination of a cleavage site of presenilin 2 protein in stably transfected SHSY5Y human neuroblastoma cell lines. Biochem Biophys Res Commun 240:728-731.

Shirotani K, Tomioka M, Kremmer E, Haass C, Steiner H (2007) Pathological activity of familial Alzheimer's disease-associated mutant presenilin can be executed by six different gamma-secretase complexes. Neurobiol Dis 27:102-107.

Steiner H, Romig H, Grim MG, Philipp U, Pesold B, Citron M, Baumeister R, Haass C (1999a) The biological and pathological function of the presenilin-1 Deltaexon 9 mutation is independent of its defect to undergo proteolytic processing. J Biol Chem 274:7615-7618.

Steiner H, Romig H, Pesold B, Philipp U, Baader M, Citron M, Loetscher H, Jacobsen H, Haass C (1999b) Amyloidogenic function of the Alzheimer's disease-associated presenilin 1 in the absence of endoproteolysis. Biochemistry 38:14600-14605.

Steiner H, Duff K, Capell A, Romig H, Grim MG, Lincoln S, Hardy J, Yu X,
Picciano M, Fechteler K, Citron M, Kopan R, Pesold B, Keck S, Baader M, Tomita T, Iwatsubo T, Baumeister R, Haass C (1999c) A loss of function mutation of presenilin-2 interferes with amyloid beta-peptide production and notch signaling. J Biol Chem 274:28669-28673.

Steiner H, Kostka M, Romig H, Basset G, Pesold B, Hardy J, Capell A, Meyn L, Grim ML, Baumeister R, Fechteler K, Haass C (2000) Glycine 384 is required for presenilin-1 function and is conserved in bacterial polytopic aspartyl proteases. Nat Cell Biol 2:848-851.

Steiner H, Fluhrer R, Haass C (2008) Intramembrane proteolysis by gamma-secretase. J Biol Chem 283:29627-29631.

Struhl G, Adachi A (2000) Requirements for presenilin-dependent cleavage of notch and other transmembrane proteins. Mol Cell 6:625-636.

Takami M, Nagashima Y, Sano Y, Ishihara S, Morishima-Kawashima M, Funamoto S, Ihara Y (2009) $\gamma$-Secretase: successive tripeptide and tetrapeptide release from the transmembrane domain of $\beta$-carboxyl terminal fragment. J Neurosci 29:13042-13052.

Thinakaran G, Borchelt DR, Lee MK, Slunt HH, Spitzer L, Kim G, Ratovitsky T, Davenport F, Nordstedt C, Seeger M, Hardy J, Levey AI, Gandy SE, Jenkins NA, Copeland NG, Price DL, Sisodia SS (1996) Endoproteolysis of presenilin 1 and accumulation of processed derivatives in vivo. Neuron 17:181-190.

Thinakaran G, Regard JB, Bouton CM, Harris CL, Price DL, Borchelt DR, Sisodia SS (1998) Stable association of presenilin derivatives and absence of presenilin interactions with APP. Neurobiol Dis 4:438-453.

Tolia A, Chávez-Gutiérrez L, De Strooper B (2006) Contribution of presenilin transmembrane domains 6 and 7 to a water-containing cavity in the gamma-secretase complex. J Biol Chem 281:27633-27642.

Tolia A, Horré K, De Strooper B (2008) Transmembrane domain 9 of presenilin determines the dynamic conformation of the catalytic site of gamma-secretase. J Biol Chem 283:19793-19803.

Walter J, Grünberg J, Capell A, Pesold B, Schindzielorz A, Citron M, Mendla K, George-Hyslop PS, Multhaup G, Selkoe DJ, Haass C (1997) Proteolytic processing of the Alzheimer disease-associated presenilin-1 generates an in vivo substrate for protein kinase C. Proc Natl Acad Sci U S A 94:5349-5354.

Wang J, Brunkan AL, Hecimovic S, Walker E, Goate A (2004) Conserved "PAL" sequence in presenilins is essential for gamma-secretase activity, but not required for formation or stabilization of gamma-secretase complexes. Neurobiol Dis 15:654-666.

Wang J, Beher D, Nyborg AC, Shearman MS, Golde TE, Goate A (2006) C-terminal PAL motif of presenilin and presenilin homologues required for normal active site conformation. J Neurochem 96:218-227.

Weidemann A, Eggert S, Reinhard FB, Vogel M, Paliga K, Baier G, Masters CL, Beyreuther K, Evin G (2002) A novel epsilon-cleavage within the transmembrane domain of the Alzheimer amyloid precursor protein demonstrates homology with Notch processing. Biochemistry 41:28252835.

Wolfe MS (2009) Intramembrane-cleaving proteases. J Biol Chem 284: 13969-13973.

Wolfe MS, Xia W, Ostaszewski BL, Diehl TS, Kimberly WT, Selkoe DJ (1999) Two transmembrane aspartates in presenilin-1 required for presenilin endoproteolysis and gamma-secretase activity. Nature 398:513-517.

Xia W (2003) Relationship between presenilinase and gamma-secretase. Drug News Perspect 16:69-74.

Xia W (2008) From presenilinase to gamma-secretase, cleave to capacitate. Curr Alzheimer Res 5:172-178.

Yamasaki A, Eimer S, Okochi M, Smialowska A, Kaether C, Baumeister R, Haass C, Steiner H (2006) The GxGD motif of presenilin contributes to catalytic function and substrate identification of $\gamma$-secretase. J Neurosci 26:3821-3828.

Yu G, Chen F, Levesque G, Nishimura M, Zhang DM, Levesque L, Rogaeva E, Xu D, Liang Y, Duthie M, St George-Hyslop PH, Fraser PE (1998) The presenilin 1 protein is a component of a high molecular weight intracellular complex that contains beta-catenin. J Biol Chem 273:16470-16475.

Zhao B, Yu M, Neitzel M, Marugg J, Jagodzinski J, Lee M, Hu K, Schenk D, Yednock T, Basi G (2008) Identification of gamma-secretase inhibitor potency determinants on presenilin. J Biol Chem 283:2927-2938.

Zhao G, Mao G, Tan J, Dong Y, Cui MZ, Kim SH, Xu X (2004) Identification of a new presenilin-dependent zeta-cleavage site within the transmembrane domain of amyloid precursor protein. J Biol Chem 279: 50647-50650. 